\title{
Relationship between processing score and kernel-fraction particle size in whole-plant corn silage
}

\author{
G. S. Dias Junior, ${ }^{\star} \dagger$ L. F. Ferraretto, ${ }^{\star}$ G. G. S. Salvati, ${ }^{\star}$ L. C. de Resende, ${ }^{\star} \dagger$ P. C. Hoffman, ${ }^{*}$ M. N. Pereira, $\dagger$ \\ and R. D. Shaver*1 \\ *Department of Dairy Science, University of Wisconsin, Madison 53706 \\ †Departamento de Zootecnia, Universidade Federal de Lavras, Lavras, MG 37200-000, Brazil
}

\begin{abstract}
Kernel processing increases starch digestibility in whole-plant corn silage (WPCS). Corn silage processing score (CSPS), the percentage of starch passing through a $4.75-\mathrm{mm}$ sieve, is widely used to assess degree of kernel breakage in WPCS. However, the geometric mean particle size (GMPS) of the kernel-fraction that passes through the $4.75-\mathrm{mm}$ sieve has not been well described. Therefore, the objectives of this study were (1) to evaluate particle size distribution and digestibility of kernels cut in varied particle sizes; (2) to propose a method to measure GMPS in WPCS kernels; and (3) to evaluate the relationship between CSPS and GMPS of the kernel fraction in WPCS. Composite samples of unfermented, dried kernels from 110 corn hybrids commonly used for silage production were kept whole $(\mathrm{WH})$ or manually cut in $2,4,8,16,32$ or 64 pieces $(2 \mathrm{P}$, $4 \mathrm{P}, 8 \mathrm{P}, 16 \mathrm{P}, 32 \mathrm{P}$, and $64 \mathrm{P}$, respectively). Dry sieving to determine GMPS, surface area, and particle size distribution using 9 sieves with nominal square apertures of $9.50,6.70,4.75,3.35,2.36,1.70,1.18$, and $0.59 \mathrm{~mm}$ and pan, as well as ruminal in situ dry matter (DM) digestibilities were performed for each kernel particle number treatment. Incubation times were $0,3,6,12$, and $24 \mathrm{~h}$. The ruminal in situ DM disappearance of unfermented kernels increased with the reduction in particle size of corn kernels. Kernels kept whole had the lowest ruminal DM disappearance for all time points with maximum DM disappearance of $6.9 \%$ at $24 \mathrm{~h}$ and the greatest disappearance was observed for $64 \mathrm{P}$, followed by $32 \mathrm{P}$ and 16P. Samples of WPCS $(n=80)$ from 3 studies representing varied theoretical length of cut settings and processor types and settings were also evaluated. Each WPCS sample was divided in 2 and then dried at $60^{\circ} \mathrm{C}$ for $48 \mathrm{~h}$. The CSPS was determined in duplicate on 1 of the split samples, whereas on the other split
\end{abstract}

Received September 16, 2015

Accepted December 11, 2015.

${ }^{1}$ Corresponding author: rdshaver@wisc.edu sample the kernel and stover fractions were separated using a hydrodynamic separation procedure. After separation, the kernel fraction was redried at $60^{\circ} \mathrm{C}$ for $48 \mathrm{~h}$ in a forced-air oven and dry sieved to determine GMPS and surface area. Linear relationships between CSPS from WPCS $(\mathrm{n}=80)$ and kernel fraction GMPS, surface area, and proportion passing through the 4.75$\mathrm{mm}$ screen were poor. Strong quadratic relationships between proportion of kernel fraction passing through the $4.75-\mathrm{mm}$ screen and kernel fraction GMPS and surface area were observed. These findings suggest that hydrodynamic separation and dry sieving of the kernel fraction may provide a better assessment of kernel breakage in WPCS than CSPS.

Key words: corn silage, particle size, corn silage processing score

\section{INTRODUCTION}

Whole-plant corn silage (WPCS) is a high-energy forage with high DM yield per hectare from kernel and stover fractions, which are high in starch and NDF contents, respectively. The kernel fraction, composed of approximately $72 \%$ starch (DM basis; Huntington, 1997), represents nearly $45 \%$ of the whole-plant DM (Philippeau and Michalet-Doreau, 1998) and more than $50 \%$ of the energy in WPCS (calculated using NRC, 2001). Total-tract starch digestibility of WPCS, however, ranges from about 80 to $98 \%$ in lactating dairy cows fed WPCS-based diets (Ferraretto and Shaver, 2012b). Processing WPCS through rollers during harvest reduces the particle size of corn kernels and has been reported to increase total-tract starch digestibility (Bal et al., 2000; Johnson et al., 2002; Cooke and Bernard, 2005). Nevertheless, the efficacy of kernel processing in WPCS is variable and can be influenced by several factors, including maturity or DM content of WPCS at harvest, theoretical length of cut, type of processor, and processor roll-gap clearance (Shinners et al., 2000; Ferraretto and Shaver, 2012a,b). Therefore, methods to evaluate the adequacy of kernel processing in WPCS are critical. 
Ferreira and Mertens (2005) established a methodology to determine degree of kernel breakage in WPCS defined as corn silage processing score (CSPS). This methodology is widely used in the dairy industry and measures the proportion of starch passing through a $4.75-\mathrm{mm}$ sieve after vertical shaking separation procedures using dried WPCS samples. However, the use of a single sieve to determine degree of kernel processing leads to the assumption that all particles passing through this sieve are equal. It is unknown, however, if the proportion of different fragments comprising this pool of particles vary widely. Wide variation would suggest that differences in starch digestibility among WPCS samples of similar CSPS exist.

Mean particle size is a mathematical function that describes the degree of reduction of a set of particles and is defined by measuring the relative amounts of particles retained in varied sieves of known dimensions (Liu, 2008). Particle size distribution analysis is desirable in several fields that handle granular or particulate materials. Granulometry is a common method to determine the particle size distribution of feed materials (Clementson and Ileleji, 2012), which can be performed with dry sieving. The material passes through a series of sieves, which are individually weighed and the proportion of material retained on each sieve determined. Geometric mean particle size (GMPS) is the most common method used for comparison of particle size distribution in cereal grains (ASABE, 2007). Recently, GMPS has been suggested, in combination with zein protein or ammonia-N, for modeling ruminal and totaltract starch digestibilities and rate of ruminal starch digestion for dry and high-moisture corns (Hoffman et al., 2012a). The GMPS of the kernel fraction in WPCS has not been well described and may provide valuable insights for modeling starch digestibility in WPCS. Thus, the objectives of our study were to evaluate (1) particle size distribution and ruminal in situ DM disappearance of unfermented kernels cut in varied particle sizes; (2) a method to measure GMPS in WPCS kernels; and (3) the relationship between CSPS and hydrodynamically separated kernel fraction GMPS in WPCS.

\section{MATERIALS AND METHODS}

\section{Unfermented Kernels}

Unfermented kernels from 110 corn hybrids from varied genetic lines commonly used for silage production were obtained from previous experiments in our laboratory. Kernels were collected from middle portions of ears at the maturity stage between one-half and twothirds of the milk line. All kernels were previously dried at $40^{\circ} \mathrm{C}$ for $72 \mathrm{~h}$ in a forced-air oven. Kernels were kept whole (WH) or manually cut in $2,4,8,16,32$, or 64 pieces $(\mathbf{2 P}, \mathbf{4 P}, \mathbf{8 P}, \mathbf{1 6 P}, \mathbf{3 2 P}$, and $\mathbf{6 4 P}$, respectively) using scalpel blades (Surgical blade stainless steel n.21, Feather Safety Razor Co., Ltd., Ozaka, Japan). The first cut was done across the kernel, and each subsequent cut halved a previously cut piece. A total of 330 kernels (3 per hybrid) were obtained for each particle number treatment. Throughout the manuscript these treatments will be referred to as a kernel particle number treatment. Each sample $(128.2 \pm 7.0$ g; mean \pm SD) was dry-sieved using a Tyler Ro-Tap Shaker (model RX-29, W.S. Tyler, Mentor, OH) using a set of 9 sieves (W.S. Tyler) with nominal square apertures of $9.50,6.70,4.75,3.35,2.36,1.70,1.18$, and $0.59 \mathrm{~mm}$ and pan (ASABE, 2007) to determine particle size distribution; GMPS $(\mu \mathrm{m})$ and surface area $\left(\mathrm{cm}^{2} / \mathrm{g}\right)$ were calculated using a log normal distribution (Baker and Herrman, 2002). Sieves were a combination of sieves used for CSPS (Ferreira and Mertens, 2005; 9.50-, 6.70-, 4.75-, 2.36-, 1.18-, and 0.59-mm sieves) or dry ground corn GMPS (Baker and Herrman, 2002; 3.35- and $1.70-\mathrm{mm}$ sieves). The associated use of these 2 sets of sieves was chosen in an attempt to better characterize and describe the particle size distributions (\% of DM retained on each sieve).

Subsequently, in situ measurements of ruminal DM disappearance were performed for each kernel particle number treatment using 2 ruminally cannulated, midlactation, multiparous Holstein cows fed a TMR containing (DM basis) alfalfa silage (44.5\%), nonexperimental corn silage $(26.8 \%)$, alfalfa hay $(10.7 \%)$, wheat straw $(6.5 \%)$, and concentrate mixture (11.5\%). Individual samples of each kernel particle number treatment were recombined from each of the sieves after dry sieving procedures and evaluated for DM disappearance. Dacron polyester cloth bags (R510, $10 \times 20 \mathrm{~cm}$ and $50-\mu \mathrm{m}$ pores; Ankom Techonology, Macedon, NY) containing approximately $5 \mathrm{~g}$ of DM of each unfermented kernel particle number treatment, yielding a ratio of sample mass per bag area of $25 \mathrm{mg} / \mathrm{cm}^{2}$, were incubated in duplicate within each cow. The in situ bags for the respective treatments for each time point $(3,6,12$, and 24 h) were placed in a nylon laundry bag $(30 \times 40 \mathrm{~cm})$ and then positioned in the ventral rumen of each cow. Each laundry bag was attached to the inside of the rumen cannula with a $75-\mathrm{cm}$ long nylon rope and contained a rubber weight to ensure they remained submerged in the ruminal contents. Bags were moistened in warm water for $30 \mathrm{~s}$ before incubation. Each laundry bag contained a blank bag to allow correction for infiltration of DM into sample bags. After removal, samples were soaked in cold water for 15 min before washing twice in 
a commercial washing machine (Whirlpool \#3347019A, Whirlpool Corp., Benton Harbor, MI) using the regular cycle rinse setting with cold water for 12-min cycles (Cherney et al., 1990). Two bags for each treatment (0-h bags) were soaked for $30 \mathrm{~min}$ in tepid water and washed with the rest of the sample bags. Bags were dried together in a forced-air oven at $60^{\circ} \mathrm{C}$ for $48 \mathrm{~h}$. The mean DM disappearance value of the 2 bags on a treatment per incubation time was calculated for each cow.

In situ data were analyzed using PROC MIXED (SAS Institute, 2004). The model included the fixed effect of treatment, hour, and the interaction of treatment and hour, and cow as a random effect. Statistical analyses were performed on 0-h bags using PROC MIXED (SAS Institute, 2004) and the fixed effect of treatment. Means were determined using the least squares means statement and treatment means were compared using the Bonferroni's $t$-test option after a significant overall treatment F-test. Bonferroni's $t$-test is a sequentially rejective test based on the Holm-Bonferroni method (Holm, 1979). Interaction effects were partitioned using the SLICE option (SAS Institute, 2004). Subsequently, regression analysis was performed using PROC REG of SAS (SAS Institute, 2004) to determine linear and quadratic relationships between ruminal in situ DM disappearance and GMPS or surface area. Analyses were performed on all the individual time point treatment means. Best fit regression (linear or quadratic) was chosen using the highest coefficient of determination $\left(\mathrm{R}^{2}\right)$ and lowest root mean square error (RMSE) as indicators. Statistical significance and tendencies were declared at $P \leq 0.05$ and $P>0.05$ to $P<0.10$, respectively.

\section{WPCS}

Eighty WPCS samples from 2 feeding trials (Ferraretto and Shaver, 2012a; Vanderwerff et al., 2015) and a field survey of commercial farms (Salvati et al., 2015) were selected to represent varied corn silage harvesting equipment, processor types, and settings. Samples were frozen and stored at $-20^{\circ} \mathrm{C}$ in all 3 studies and thawed overnight before sample analysis. Each WPCS sample was placed in a bucket, homogenized manually, and divided into two 1-kg subsamples using a quartering technique: homogeneous samples were divided into 4 equal subsamples. Two subsamples allocated diagonally were rehomogenized and saved as 1 subsample, whereas the other 2 subsamples were rehomogenized and saved as the other subsample. Each subsample was dried at $60^{\circ} \mathrm{C}$ for $48 \mathrm{~h}$ in a forced-air oven. On 1 of the subsamples, CSPS was determined in duplicate as described by Ferreira and Mertens (2005). On the other subsample, kernel and stover fractions were separated by a hydrodynamic separation procedure (Savoie et al., 2004). This method is based on differences in buoyancy between the kernels and stover. Each sample of approximately $400 \mathrm{~g}$ of DM was placed in a $10-\mathrm{L}$ rectangular tub containing $7 \mathrm{~L}$ of water. Each dried sample was gently agitated manually for $2 \mathrm{~min}$ such that the entire sample was submerged in water. After $2 \mathrm{~min}$, the stover fraction, which floats due to a lower density than water, was removed gently using a small 1.17-mm sieve (Savoie et al., 2004). Subsequently, the water was poured out of the tub, retaining the kernel fraction, which has a density greater than water (Savoie et al., 2004). After separation, the kernel fraction was transferred to aluminum plates, redried at $60^{\circ} \mathrm{C}$ for 48 $\mathrm{h}$ in a forced-air oven, and dry sieved using a Tyler Ro-Tap Shaker (model RX-29, W.S. Tyler) with a set of 9 sieves having nominal square apertures of 9.50, $6.70,4.75,3.35,2.36,1.70,1.18$, and $0.59 \mathrm{~mm}$ and pan; GMPS $(\mu \mathrm{m})$ and surface area $\left(\mathrm{cm}^{2} / \mathrm{g}\right)$ were calculated using a log normal distribution (Baker and Herrman, 2002). All samples were recombined and ground to pass through a 1-mm screen of a Wiley mill (Thomas Scientific, Swedesboro, NJ) for starch, NDF, and CP determination on hydrodynamically separated WPCS kernel fraction by near-infrared reflectance spectroscopy (NIRS; model 6500; Foss-NIR System, Silver Spring, MD). Each sample was packed into a cylindrical sample holder equipped with a quartz window (Part number 60013287; Foss-NIR System) and scanned, between 400 and 2,498 nm, as described by Mentink et al. (2006). Prediction equations for determining nutrient composition were obtained from the NIRS Forage and Feed Test Consortium website (http://nirsconsortium. org/). These equations were calibrated for CP (methods 984.13, 988.05, and 990.03; AOAC International, 2012), NDF assayed with $\alpha$-amylase and sodium sulfite (method 2002.04; AOAC International, 2012) and expressed inclusive of residual ash (aNDF), and starch (Bach Knudsen, 1997) using $754\left(\mathrm{R}^{2}=0.88\right), 1,193$ $\left(\mathrm{R}^{2}=0.93\right)$, and $320\left(\mathrm{R}^{2}=0.97\right)$ fermented WPCS samples, respectively, from participating laboratories from all over the United States and collected over more than $20 \mathrm{yr}$.

Regressions to determine linear and quadratic relationships between CSPS in WPCS and hydrodynamically separated WPCS kernel fraction GMPS, surface area, and retained proportion on sieves of varied particle size were performed using PROC REG of SAS (SAS Institute, 2004). Best fit regression (linear or quadratic) was chosen using the highest $\mathrm{R}^{2}$ and lowest RMSE as indicators. Statistical significance and tendencies were declared at $P \leq 0.05$ and $P>0.05$ to $P \leq$ 0.10 , respectively. 
Table 1. Particle size distribution, geometric mean particle size (GMPS), and surface area of unfermented kernels ${ }^{1}$

\begin{tabular}{|c|c|c|c|c|c|c|c|}
\hline Item & WH & $2 \mathrm{P}$ & $4 \mathrm{P}$ & $8 \mathrm{P}$ & $16 \mathrm{P}$ & $32 \mathrm{P}$ & $64 \mathrm{P}$ \\
\hline 9.50 & 0.00 & 0.00 & 0.00 & 0.00 & 0.00 & 0.00 & 0.00 \\
\hline 3.35 & 0.00 & 0.67 & 38.34 & 87.98 & 15.81 & 0.57 & 0.00 \\
\hline 2.36 & 0.00 & 0.00 & 0.20 & 5.01 & 74.23 & 53.74 & 3.97 \\
\hline 1.70 & 0.00 & 0.00 & 0.02 & 0.18 & 7.78 & 43.42 & 65.01 \\
\hline Pan & 0.00 & 0.21 & 0.15 & 0.52 & 0.45 & 0.31 & 3.85 \\
\hline GMPS, $\mu \mathrm{m}$ & $7,556.7$ & $6,074.9$ & $4,980.8$ & $3,953.4$ & $2,866.7$ & $2,413.7$ & $1,683.3$ \\
\hline Surface area, $\mathrm{cm}^{2} / \mathrm{g}$ & 3.6 & 6.5 & 8.9 & 11.9 & 15.9 & 17.8 & 23.2 \\
\hline
\end{tabular}

${ }^{1}$ Kernels were kept whole $(\mathrm{WH})$ or broken in $2,4,8,16,32$, or 64 pieces $(2 \mathrm{P}, 4 \mathrm{P}, 8 \mathrm{P}, 16 \mathrm{P}, 32 \mathrm{P}$, and $64 \mathrm{P}$, respectively).

${ }^{2}$ Percentage of particles retained on each sieve (DM basis).

Simulations were performed using the Feed Grain V2.0 Evaluation System (Hoffman et al., 2012b) to predict the potential effect of GMPS on extents of ruminal and total-tract starch digestibilities and ruminal rate of starch digestibility for dairy cows. The full model description can be accessed in Hoffman et al. (2012c). Briefly, the Feed Grain V2.0 Evaluation System is based on the model proposed by Hoffman et al. (2012a) and uses GMPS and ammonia-N or prolamin to predict starch digestibility of HMC or dry corn, respectively. Hydrodynamically separated WPCS kernel fraction GMPS measurements from all samples were input in the model at a constant ammonia- $\mathrm{N}$ concentration value $(3.3 \pm 2.2 \% \mathrm{CP})$. Ammonia-N concentration was arbitrarily chosen based on the average of ammonia$\mathrm{N}$ values of high-moisture corn samples with a similar storage length (Ferraretto et al., 2014).

\section{RESULTS AND DISCUSSION}

\section{Unfermented Kernels}

Particle size distribution of unfermented kernels is in Table 1. As designed, the distribution of particles among the different sieves varied widely among kernel particle number treatments. It was observed that each sieve retained more than one kernel particle number treatment. The least numeric variation was observed for $8 \mathrm{P}$ with $88 \%$ of the particles retained on the 3.35 $\mathrm{mm}$ sieve. In contrast, $64 \mathrm{P}$ was the most numerically variable with material retained on 2.36-, 1.70-, 1.18-, and $0.59-\mathrm{mm}$ sieves, and pan. This is related to wide variation in kernel size comprising the pool of hybrids evaluated and the corresponding difference in particle size when small and large kernels were cut in 64P. Kernel size naturally varies within and across hybrids (Graven and Carter, 1990) and may be affected by vary- ing vigor, environmental conditions during pollination and fill period, kernel position in the ear, and parent tendencies (EnayatGholizadeh et al., 2012; Mondo et al., 2013). In addition, kernels were cut by hand; therefore, samples from the same kernel may vary in particle size. Ferreira and Mertens (2005) proposed CSPS, the proportion of starch passing through a $4.75-\mathrm{mm}$ sieve, as a quantitative measure of kernel fragmentation in WPCS. Those authors suggested that CSPS represents the proportion of kernels that are broken in at least one-fourth of a kernel. Our results, however, revealed that $60 \%$ of $4 \mathrm{P}$ kernels were retained on the $4.75-\mathrm{mm}$ sieve. Perhaps the use of a broader hybrid pool and use of dried, unfermented kernels in the present study may explain some of the differences between studies.

Ruminal in situ DM disappearance of each particle number treatment of unfermented kernels is in Table 2. Digestibility of DM in corn kernels is strongly related to starch digestibility (Philippeau and Michalet-Doreau, 1999; Ngonyamo-Majee et al., 2009), and thus served as a proxy for starch digestibility in the present study. Treatments followed a similar pattern across all time points, but a treatment $\times$ time interaction was observed $(P=0.01)$, as the magnitude of response over time was different for the different treatments. A negative quadratic relationship was observed between GMPS and ruminal in situ DM disappearance for all time points (Figure 1; $P<0.01$ ), with the lowest $\mathrm{R}^{2}$ observed at 3 $\mathrm{h}\left(\mathrm{R}^{2}=0.89\right)$. Overall, ruminal DM disappearance increased $(P<0.01)$ with the reduction in particle size of corn kernels. Likewise, a positive quadratic relationship was observed between surface area and ruminal in situ DM disappearance for all time points (Figure $2 ; P<$ $0.01)$, with lowest $R^{2}$ observed at $3 \mathrm{~h}$ of incubation $\left(\mathrm{R}^{2}\right.$ $=0.89)$. Reduced GMPS increased total-tract starch digestibility in dry ground and high-moisture corn (Ferraretto et al., 2013). Kernels kept whole had the lowest 


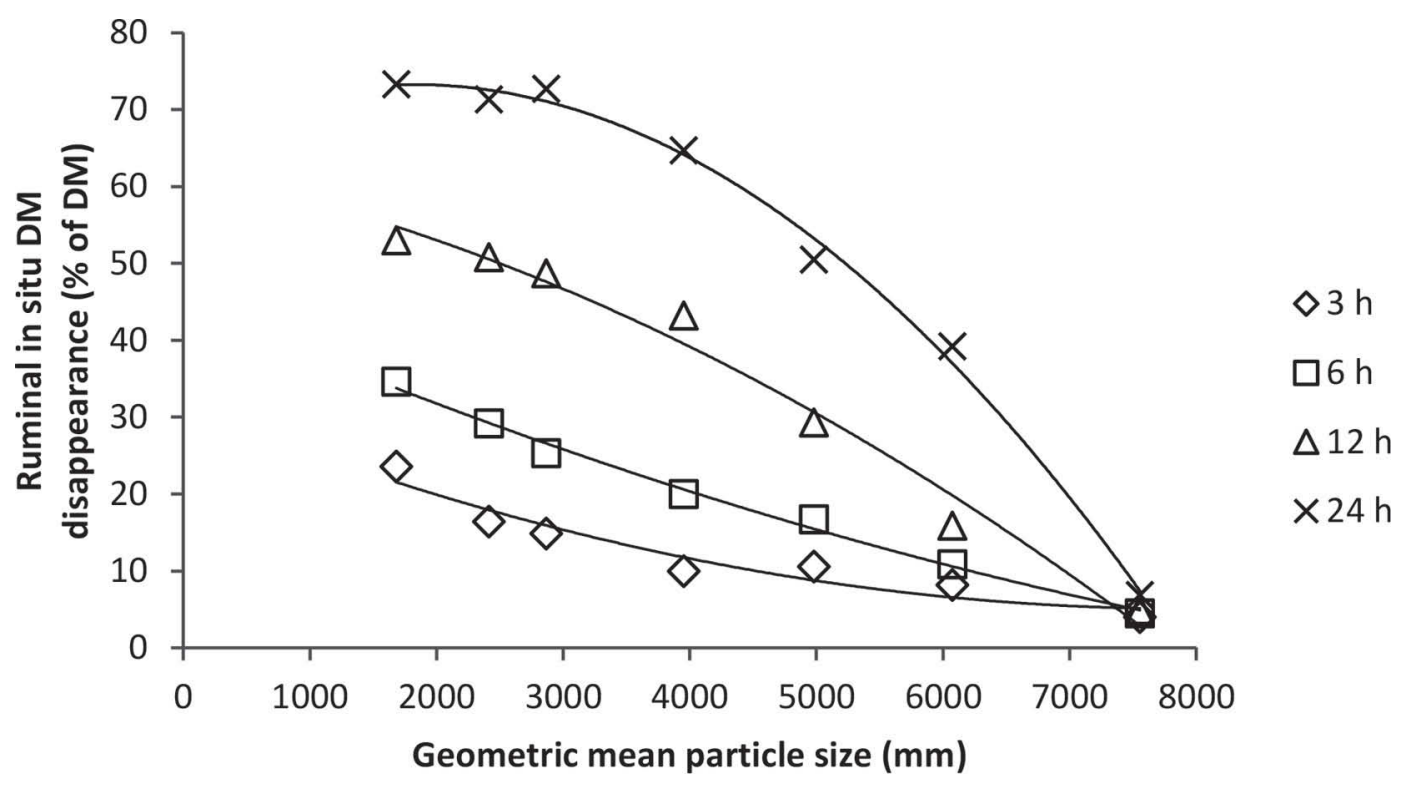

Figure 1. Relationship between ruminal in situ DM disappearance (\% of DM) and geometric mean particle size ( $\mu \mathrm{m})$ in unfermented kernels. Prediction equation for $3 \mathrm{~h}: \mathrm{y}=31.58( \pm 4.53)-0.007 \mathrm{x}( \pm 0.01)-4.170 \mathrm{x}^{2}( \pm 2.42) ; \mathrm{n}=7$, root mean square error $(\mathrm{RMSE})=2.10, \mathrm{R}^{2}=0.89$, $P=0.01$. Prediction equation for $6 \mathrm{~h}: \mathrm{y}=45.11( \pm 2.42)-0.007 \mathrm{x}( \pm 0.01)-2.428 \mathrm{x}^{2}( \pm 1.21) ; \mathrm{n}=7, \mathrm{RMSE}=1.05, \mathrm{R}^{2}=0.99, P=0.001$. Prediction equation for $12 \mathrm{~h}: \mathrm{y}=62.13( \pm 6.74)-0.004 \mathrm{x}( \pm 0.01)-5.909 \mathrm{x}^{2}( \pm 3.60) ; \mathrm{n}=7$, RMSE $=3.12, \mathrm{R}^{2}=0.97, P=0.001$. Prediction equation for $24 \mathrm{~h}: \mathrm{y}=66.65( \pm 4.47)+0.001 \mathrm{x}( \pm 0.01)-0.001 \mathrm{x}^{2}( \pm 2.39) ; \mathrm{n}=7, \mathrm{RMSE}=2.07, \mathrm{R}^{2}=0.99, P=0.001$.

ruminal DM disappearance for all time points, with a maximum DM disappearance of $6.9 \%$ at $24 \mathrm{~h}$. The pericarp layer surrounding the starch endosperm is highly resistant to microbial attachment (McAllister et al., 1994) and likely inhibited DM disappearance in WH. The greatest ruminal in situ DM disappearance was observed for $64 \mathrm{P}$, followed by $32 \mathrm{P}$ and $16 \mathrm{P}$, followed by a steady decrease in $\mathrm{DM}$ disappearance in $8 \mathrm{P}, 4 \mathrm{P}$, $2 \mathrm{P}$, and $\mathrm{WH}$. As kernel fragmentation increases, greater surface area is available for attachment of rumen microorganisms to starch granules and enzymatic digestion (McAllister et al., 1993). Furthermore, reduced GMPS attenuates the negative effects of the protein matrix encapsulating starch granules (Hoffman et al., 2011), thereby resulting in greater starch digestion. Currently, the most common method used to assess degree of kernel processing in WPCS is CSPS, which considers all particles passing through a $4.75-\mathrm{mm}$ sieve to be equal in digestibility characteristics. Nevertheless, dry sieving revealed that $4 \mathrm{P}, 8 \mathrm{P}, 16 \mathrm{P}, 32 \mathrm{P}$, and $64 \mathrm{P}$ unfermented kernel fractions with different in situ disappearance passed through this sieve. Differences in DM disappearance observed in the present study emphasize the importance of a more descriptive particle size methodology for kernels. An important aspect to consider is the use of unfermented kernels in the present study, which are well known to be less digestible than fermented kernels (Philippeau and Michalet-Doreau, 1998; Hoffman et al., 2011). Perhaps differences in DM disappearance among the varied unfermented kernel particle number treat-

Table 2. Ruminal in situ DM disappearance (\% of DM) of unfermented kernels ${ }^{1,2,3}$

\begin{tabular}{|c|c|c|c|c|c|c|c|c|c|}
\hline Time point, $\mathrm{h}$ & WH & $2 \mathrm{P}$ & $4 \mathrm{P}$ & $8 \mathrm{P}$ & $16 \mathrm{P}$ & $32 \mathrm{P}$ & $64 \mathrm{P}$ & $\mathrm{SEM}^{4}$ & $P$-value \\
\hline 3 & $4.0^{\mathrm{c}}$ & $8.2^{\mathrm{b}}$ & $10.6^{\mathrm{b}}$ & $10.0^{\mathrm{b}}$ & $14.9^{\mathrm{b}}$ & $16.4^{\mathrm{ab}}$ & $23.6^{\mathrm{a}}$ & 6.1 & 0.03 \\
\hline 6 & $4.5^{\mathrm{d}}$ & $10.9^{\mathrm{c}}$ & $16.7^{\mathrm{bc}}$ & $20.0^{\mathrm{b}}$ & $25.3^{\mathrm{ab}}$ & $29.2^{\mathrm{a}}$ & $34.6^{\mathrm{a}}$ & 6.1 & 0.001 \\
\hline 24 & $6.9^{\mathrm{e}}$ & $39.2^{\mathrm{d}}$ & $50.5^{\mathrm{c}}$ & $64.7^{\mathrm{b}}$ & $72.7^{\mathrm{ab}}$ & $71.3^{\mathrm{a}}$ & $73.3^{\mathrm{a}}$ & 6.1 & 0.001 \\
\hline
\end{tabular}

${ }^{\mathrm{a} e}$ Means in the same row with different superscripts differ $(P \leq 0.05)$.

${ }^{1}$ Kernels were kept whole $(\mathrm{WH})$ or broken in $2,4,8,16,32$, or 64 pieces $(2 \mathrm{P}, 4 \mathrm{P}, 8 \mathrm{P}, 16 \mathrm{P}, 32 \mathrm{P}$, and $64 \mathrm{P}$, respectively).

${ }^{2}$ Hour $(P=0.001)$ and treatment by hour $(P=0.001)$ effects.

${ }^{3}$ Blank bag weights before and after incubations were $3.07( \pm 0.08)$ and $3.10 \mathrm{~g}( \pm 0.08)$, respectively.

${ }^{4}$ Greatest standard error of the mean. 


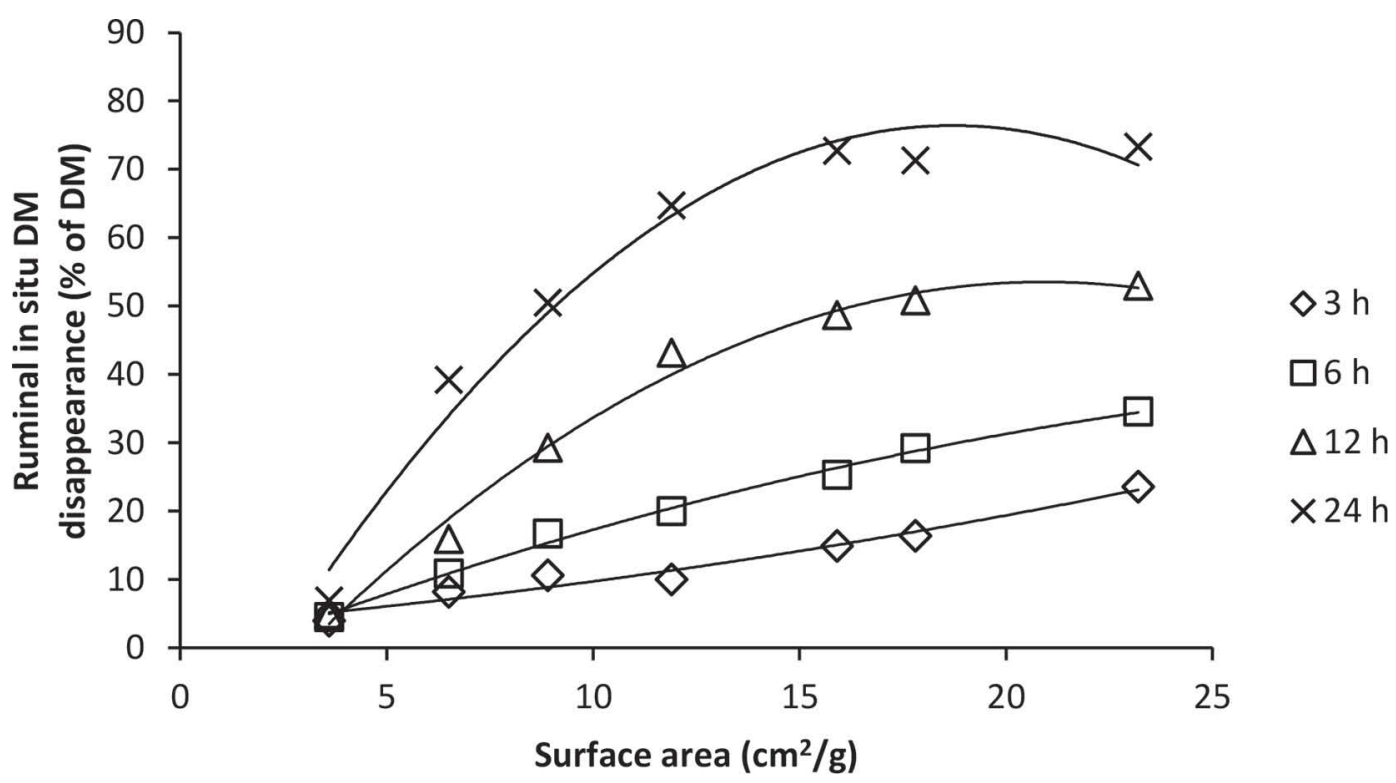

Figure 2. Relationship between ruminal in situ DM disappearance $\left(\%\right.$ of DM) and surface area $\left(\mathrm{cm}^{2} / \mathrm{g}\right)$ in unfermented kernels. Prediction equation for $3 \mathrm{~h}: \mathrm{y}=3.15( \pm 2.25)+0.507 \mathrm{x}( \pm 0.39)+0.015 \mathrm{x}^{2}( \pm 0.01) ; \mathrm{n}=7$, root mean square error $(\mathrm{RMSE})=0.40, \mathrm{R}^{2}=0.95, P=0.001$. Prediction equation for $6 \mathrm{~h}: \mathrm{y}=-3.186( \pm 1.50)+5.130 \mathrm{x}( \pm 0.38)-0.117 \mathrm{x}^{2}( \pm 0.01) ; \mathrm{n}=7, \mathrm{RMSE}=0.93, \mathrm{R}^{2}=0.99, P=0.001$. Prediction equation for $12 \mathrm{~h}: \mathrm{y}=-19.44( \pm 3.87)+6.979 \mathrm{x}( \pm 0.66)-0.167 \mathrm{x}^{2}( \pm 0.02) ; \mathrm{n}=7$, RMSE $=2.41, \mathrm{R}^{2}=0.98, P=0.001$. Prediction equation for $24 \mathrm{~h}: \mathrm{y}=-23.30( \pm 7.40)+10.660 \mathrm{x}( \pm 1.27)-0.285 \mathrm{x}^{2}( \pm 0.05) ; \mathrm{n}=7, \mathrm{RMSE}=4.60, \mathrm{R}^{2}=0.96, P=0.001$.

ments would be lower after ensiling. However, negative effects of increased particle size on starch digestibility by dairy cows was reported for both dry and ensiled corn in a recent meta-analysis (Ferraretto et al., 2013).

\section{WPCS}

Descriptive statistics for parameters measured on WPCS and hydrodynamically separated WPCS kernel fraction samples are in Table 3. As expected based on the diversity of the sample set, all parameters varied widely. The DM content of WPCS averaged 34.3\% ranging from 25.5 to $47.1 \%$, whereas starch content averaged $33.6 \%$ with a range of 17.1 to $42.6 \%$. The large variance in DM and starch contents among WPCS samples was reflective of various environmental factors and harvesting practices from the source trials and farms. The CSPS of WPCS samples averaged $66.2 \%$ and ranged from 49.5 to $82.6 \%$. Zwald et al. (2008), in a study with 81 WPCS samples from varied hybrids and planting and harvest dates, reported an average CSPS of $58.9 \%$ with a range of 24.5 to $89.7 \%$. Several factors, including endosperm properties (Correa et al., 2002), maturity (Johnson et al., 2002), and degree of processing (Bal et al., 2000) of WPCS alter the fragmentation of kernels and thereby the digestibility of starch (Cooke and Bernard, 2005). The CSPS values observed in the present study reflect the large variation that exists in the degree of kernel processing in WPCS. Starch content of the hydrodynamically separated WPCS kernel fraction averaged $70.6 \%$ with an 11.8-percentage-unit range (DM basis), giving a composition similar to those reported in other studies for the kernel fraction. These data highlight that the hydrodynamically separated WPCS kernels did not have contamination from other fractions. Ferreira and Mertens (2005) reported an average starch content of $63.7 \%$ (DM basis) in WPCS kernels that were hand-selected during the development of the CSPS procedure. Philippeau and MichaletDoreau (1997) and Ngonyamo-Majee et al. (2008), studying the chemical and physical characteristics of diverse corn hybrids, reported average starch concentrations of 65.0 and $70.8 \%$ (DM basis), respectively, in unfermented WPCS kernels. In the present study, concentrations of $\mathrm{CP}$ and NDF in the WPCS kernelfraction were $5.6 \pm 1.3$ and $11.0 \pm 1.7 \%$, respectively. Ferraretto et al. (2014) reported CP and NDF concentrations in high-moisture corn to be $8.1 \pm 1.7$ and $7.1 \pm$ $1.4 \%$, respectively, in a retrospective study containing more than 6,000 samples. Further research is warranted to evaluate the percentage of WPCS represented by hydrodynamically separated WPCS kernel fraction.

Relationships between WPCS CSPS and hydrodynamically separated WPCS kernel fraction particle size measurements are in Table 4. Linear relationships between CSPS and hydrodynamically separated WPCS 
kernel fraction GMPS $\left(\mathrm{R}^{2}=0.11 ; P=0.01\right)$ or surface area $\left(\mathrm{R}^{2}=0.06 ; P=0.03\right)$ were poor. A strong quadratic relationship $\left(\mathrm{R}^{2}=0.96\right)$ between CSPS and starch GMPS was previously reported by Zwald et al. (2008). A positive linear relationship between WPCS CSPS and the proportion of hydrodynamically separated WPCS kernel fraction passing through the $4.75-\mathrm{mm}$ screen was observed in the present study although the relationship was weak $\left(\mathrm{R}^{2}=0.34 ; P=\right.$ 0.001). A distribution plot of CSPS and proportion of hydrodynamically separated WPCS kernel fraction passing through the $4.75-\mathrm{mm}$ sieve (Figure 3 ) suggests that CSPS may underestimate starch passage through the $4.75-\mathrm{mm}$ sieve. Because the CSPS uses a dried whole sample, fine starch particles may be retained on coarse fiber particles. This may explain the strong quadratic relationship observed by Zwald et al. (2008) when measuring starch GMPS in whole samples. In the study of Zwald et al. (2008), NIRS was used to predict particle size of starch within undried, unground corn silage and verified that some physical characteristics also interfered in the accuracy of predictions. When spectra was obtained from samples without particles greater than $19 \mathrm{~mm}$ the prediction was improved. According to those authors, long forage particles and cobs retained on a 19-mm sieve could contain some fine particles of starch that might influence the capability of NIRS to properly predict the physical characteristics of the kernel-fraction of WPCS. Our data showed that the CSPS was inversely related to hydrodynamically separated WPCS kernel fraction material retained on $4.75-\mathrm{mm}\left(\mathrm{R}^{2}=0.26 ; P=0.001\right)$ sieves, as expected. Evaluation of fractions retained on individual sieves below the $4.75-\mathrm{mm}$ sieve revealed a positive, but poor relationships between CSPS and 3.35- $\left(\mathrm{R}^{2}=0.20 ; P<\right.$ $0.01), 2.36-\left(\mathrm{R}^{2}=0.47 ; P<0.01\right)$, and $1.70-\mathrm{mm}\left(\mathrm{R}^{2}=\right.$ $0.14 ; P<0.01)$ sieves and pan $\left(\mathrm{R}^{2}=0.26 ; P=0.02\right)$. Corn silage processing score was not related $(P>0.10)$ to hydrodynamically separated WPCS kernels retained on 1.18- and 0.59-mm sieves.

Among all evaluated hydrodynamically separated kernel fractions in WPCS, the particles retained on the 2.36-mm sieve, not the $4.75-\mathrm{mm}$ screen, had the highest relationship with CSPS. Thus, the proportion of particles retained on this screen was evaluated as a possible single screen predictor of GMPS and surface area of hydrodynamically separated WPCS kernels (Table 5). A quadratic relationship was observed $(P=0.01)$, but the relationship was relatively weak for both GMPS $\left(\mathrm{R}^{2}=0.16\right)$ and surface area $\left(\mathrm{R}^{2}=0.06\right)$. Zwald et al. (2008) also observed low prediction of CSPS when using data of WPCS particles retained on a single screen. In addition, those authors reported difficulties using NIRS to predict particles retained on 4.75- and 3.35$\mathrm{mm}$ vertical shaker screens.

The relationship between the proportion of hydrodynamically separated WPCS kernel particles passing through the $4.75-\mathrm{mm}$ screen and hydrodynamically separated GMPS of WPCS kernels or surface area are in Table 5. Strong quadratic relationships between pro-

Table 3. Descriptive statistics of nutrient composition and corn silage processing score (CSPS) in whole-plant corn silage and hydrodynamically separated kernel-fraction nutrient composition, particle size distribution, surface area, and geometric mean particle size (GMPS)

\begin{tabular}{|c|c|c|c|c|}
\hline Item & Mean & SD & Minimum & Maximum \\
\hline \multicolumn{5}{|l|}{ Whole-plant corn silage } \\
\hline $\mathrm{DM}, \%$ (as fed) & 34.3 & 3.9 & 25.5 & 47.1 \\
\hline Starch, \% of DM & 33.6 & 5.6 & 17.1 & 42.6 \\
\hline CSPS $^{1}{ }^{1} \%$ starch passing through a $4.75-\mathrm{mm}$ sieve & 66.3 & 6.1 & 49.5 & 82.7 \\
\hline \multicolumn{5}{|l|}{ Kernel fraction } \\
\hline CP. $\%$ of $\mathrm{DM}$ & 5.6 & 1.3 & 3.8 & 9.5 \\
\hline $\mathrm{NDF}, \%$ of DM & 11.0 & 1.7 & 7.7 & 16.6 \\
\hline Starch, \% of DM & 70.6 & 2.80 & 63.9 & 75.7 \\
\hline GMPS, $\mu \mathrm{m}$ & $2,637.5$ & 862.7 & $1,614.9$ & 7556.7 \\
\hline Surface area, $\mathrm{cm}^{2} / \mathrm{g}$ & 21.4 & 4.2 & 3.6 & 28.4 \\
\hline \multicolumn{5}{|l|}{ Kernel fraction retained on each sieve, $\%^{2}$} \\
\hline 6.70 & 5.5 & 4.4 & 0.4 & 25.7 \\
\hline 4.75 & 20.7 & 5.7 & 8.7 & 33.5 \\
\hline 3.35 & 18.6 & 3.3 & 11.1 & 30.0 \\
\hline 2.36 & 15.3 & 2.8 & 9.1 & 23.8 \\
\hline 1.70 & 11.5 & 1.6 & 6.9 & 15.1 \\
\hline 1.18 & 8.9 & 1.6 & 5.7 & 14.5 \\
\hline 0.59 & 10.4 & 2.4 & 5.8 & 19.2 \\
\hline Pan & 9.0 & 2.8 & 3.6 & 18.3 \\
\hline
\end{tabular}

${ }^{1}$ CSPS as in Ferreira and Mertens (2005).

${ }^{2}$ None of the samples had material retained in the $9.50-\mathrm{mm}$ sieve. 
Table 4. Linear relationship between corn silage processing score (\% starch passing through a 4.75-mm sieve) in whole-plant corn silage and hydrodynamically separated kernel-fraction geometric mean particle size (GMPS), surface area, and retained proportion on sieves of varied particle size

\begin{tabular}{|c|c|c|c|c|c|c|c|}
\hline Predicted & \multicolumn{4}{|c|}{ Parameter estimates } & \multicolumn{3}{|c|}{ Model statistics } \\
\hline GMPS, $\mu \mathrm{m}$ & $3,969.92$ & 479.52 & -22.61 & $3,969.92$ & 0.01 & 0.11 & 389.84 \\
\hline Particles retained, ${ }^{2} \mathrm{~mm}$ & 52.50 & 6.10 & -0.482 & 52.50 & $<0.01$ & 0.26 & 4.95 \\
\hline 3.35 & 2.55 & 3.65 & 0.242 & 2.55 & $<0.01$ & 0.20 & 2.97 \\
\hline 1.18 & 6.35 & 1.92 & 0.039 & 6.35 & 0.18 & 0.02 & 1.55 \\
\hline 0.589 & 5.77 & 2.95 & 0.070 & 5.77 & 0.12 & 0.03 & 2.39 \\
\hline Pan & 0.82 & 3.40 & 0.123 & 0.82 & 0.02 & 0.07 & 2.75 \\
\hline$<4.75$ & 67.75 & 4.45 & 0.403 & 67.75 & $<0.01$ & 0.34 & 3.61 \\
\hline
\end{tabular}

${ }^{1}$ Root mean square error.

${ }^{2}$ Percentage of particles retained on each sieve (DM basis).

portion of hydrodynamically separated WPCS kernel fraction passing through the 4.75-mm screen and GMPS $\left(\mathrm{R}^{2}=0.69 ; P<0.01\right)$ and surface area $\left(\mathrm{R}^{2}=0.54 ; P<\right.$ 0.01) were observed. Baker and Herrman (2002) found that surface area of kernel particles is an exponential function of GMPS. In our study, an increase in particles passing through 4.75 -mm sieve was strongly associated with a decrease in the GMPS. Nevertheless, the relationship between hydrodynamically separated WPCS kernel particles passing through the $4.75-\mathrm{mm}$ sieve and

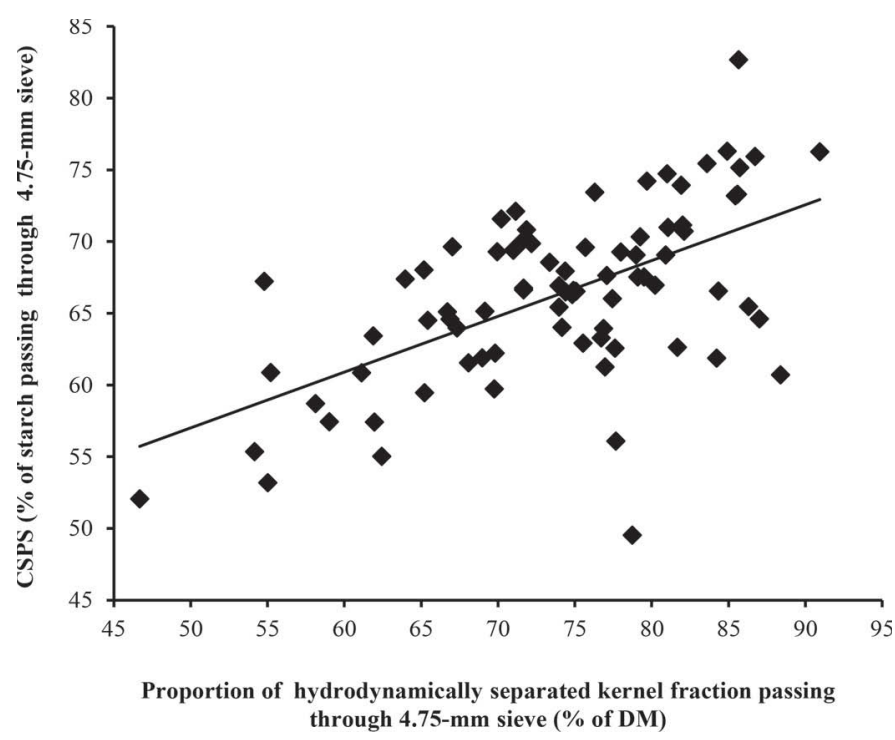

Figure 3. Relationship between corn silage processing score (CSPS; $\%$ of starch passing through a 4.75 -mm sieve) and proportion of hydrodynamically separated kernel fraction passing through a $4.75-\mathrm{mm}$ sieve in whole-plant corn silage. Corn silage processing score prediction equation: $\mathrm{y}=37.55( \pm 4.54)+0.39 \mathrm{x}( \pm 0.06) ; \mathrm{n}=80$, root mean square error $=4.96, \mathrm{R}^{2}=0.34, P<0.01$. surface area was lower. This observation was expected because samples containing different proportions of varied particle sizes result in different surface area values. The particle size of kernel fractions in WPCS is important because it can influence the digestion of starch, which is the main source of digestible energy in WPCS. High demand exists for improved accuracy of predicting WPCS starch digestibility using laboratory assays, such as CSPS. Considering the great diversity in shape and size of the kernels in hybrids used for WPCS production, to define kernel processing based on the proportion of starch that passes through the $4.75-\mathrm{mm}$ sieve may not be accurate. However, CSPS remains a useful tool to evaluate kernel processing in WPCS until a new method is fully adopted by commercial laboratories. Additionally, the use of a single larger screen may lead to an underestimation of the kernel digestibility; whereas the use of a single smaller screen may overestimate the digestion potential of the kernel fraction of WPCS. Total-tract starch digestibility of corn silagebased diets is highly variable (Ferraretto and Shaver, $2012 b$ ). This variation can be partially explained by the particle size of the kernel fraction. However, building relationships between digestibility and degree of kernel fragmentation is challenging due to lack of quantitative particle size data.

Simulation results of starch fermentation rate as well as ruminal and total-tract starch digestibility are in Figure $4 \mathrm{~A}, 4 \mathrm{~B}$, and $4 \mathrm{C}$, respectively. The predicted starch fermentation rate ranged from 12.9 to $19.8 \% / \mathrm{h}$. The model predicted ruminal and total-tract starch digestibility had differences of 10.6 and 3.4 percentage units, respectively, between minimum and maximum reported values. The understanding of fermentation rate and starch digestibility of WPCS would allow dairy 
nutritionists to optimize diet formulation and thereby better meet the nutrient demands of high-producing dairy cows.

\section{CONCLUSIONS}

Particle size distribution of unfermented corn kernels cut in varied particle sizes revealed that only $40 \%$ of the kernels cut in 4 pieces passed through the 4.75$\mathrm{mm}$ sieve. Measurements of ruminal in situ DM disappearance indicated that kernels of smaller particle

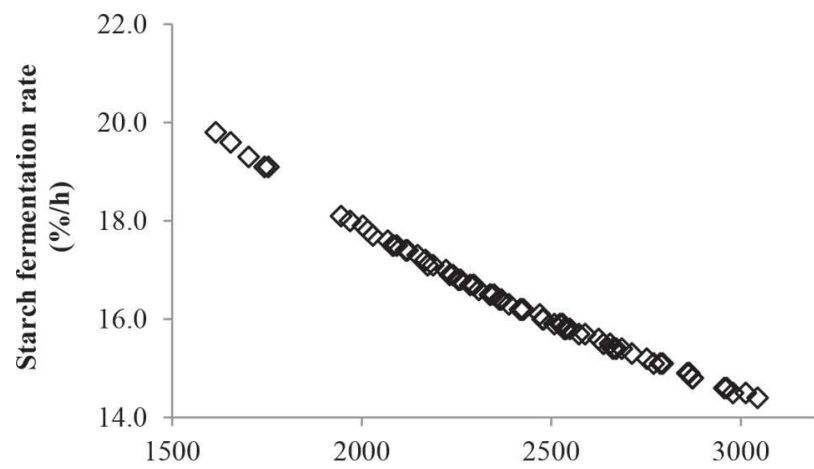

A
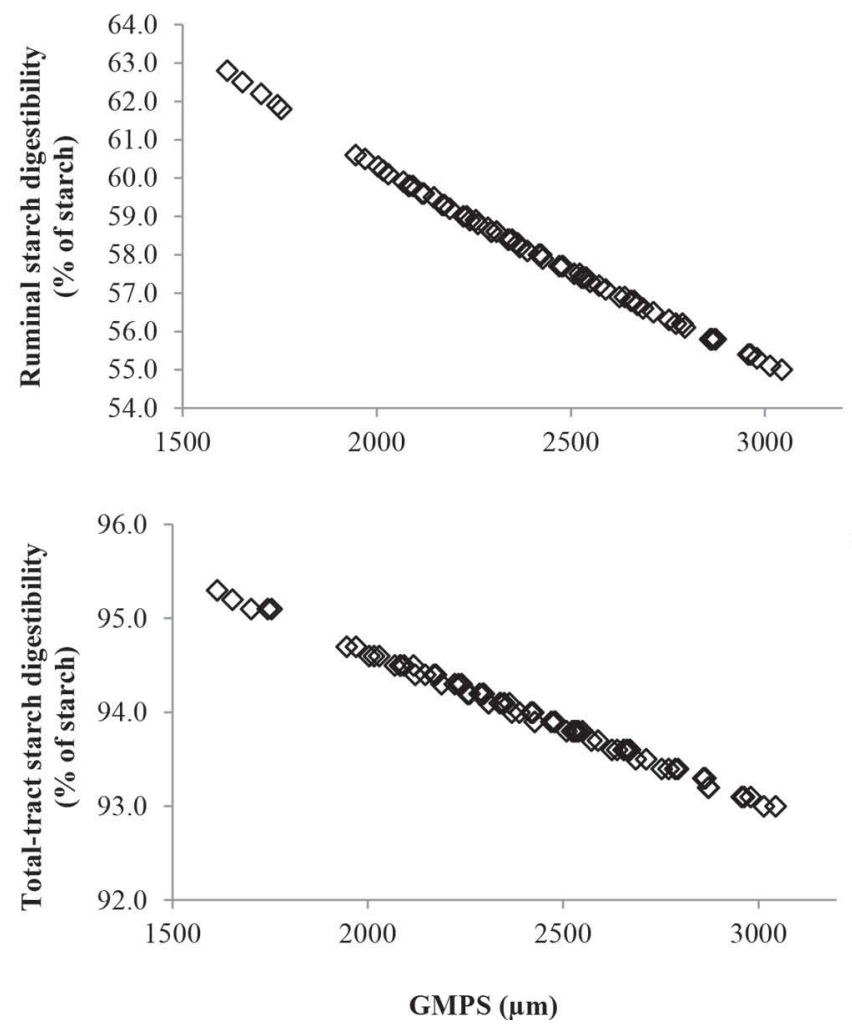

Figure 4. Simulations of the effect of kernel fraction geometric mean particle size $(\mu \mathrm{m})$ on starch fermentation rate $(\% / \mathrm{h} ; \mathrm{A})$ and ruminal and total-tract starch digestibilities (\% of starch; B and C, respectively) performed using the Feed Grain V2.0 Evaluation System (Hoffman et al., 2012b).

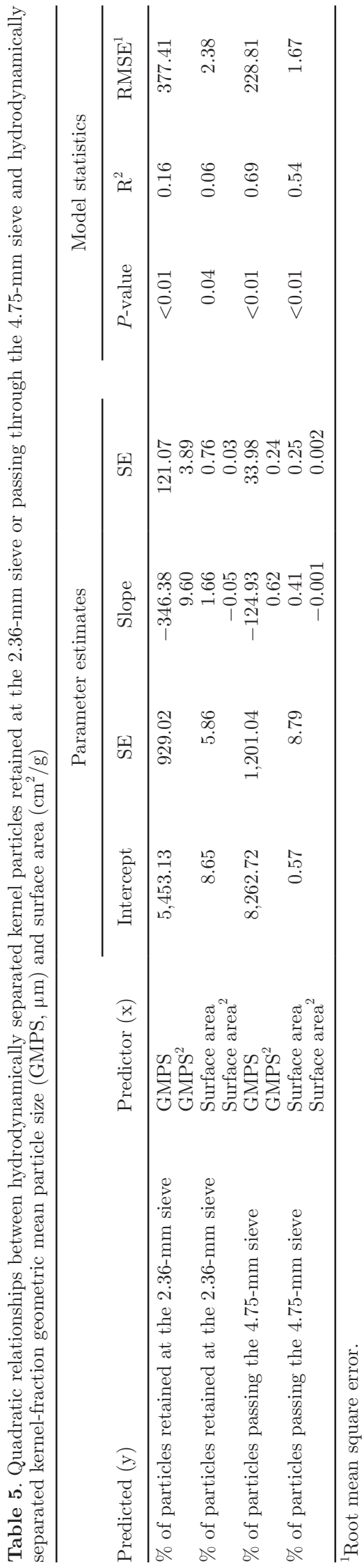

Journal of Dairy Science Vol. 99 No. 4, 2016 
sizes have increased in situ DM disappearance. Consequently, the utilization of a single sieve to assess the potential digestibility of kernels in WPCS may be too inaccurate for use in ruminant nutrition models to estimate the nutritive value of WPCS. Hydrodynamically separated WPCS kernel-fraction GMPS and surface area were poorly related to CSPS. These data suggest that hydrodynamic separation and dry-sieving of the kernel-fraction may provide a better assessment of kernel breakage in WPCS. The use of these procedures in combination with the Feed Grain V2.0 Evaluation System may enhance the modeling of starch digestibility in WPCS and further research is warranted.

\section{ACKNOWLEDGMENTS}

The authors are grateful to the Brazilian Federal Agency for Post-graduate Education (CAPES; Brasilia, DF, Brazil) for the financial support to G. S. Dias Júnior. Appreciation is also extended to Dan Undersander (Department of Agronomy, University of Wisconsin, Madison) for the opportunity to use his laboratory and NIRS equipment for nutrient analysis, and to USDA Hatch Act Formula (fund \#WIS10719; Washington, DC) for partial project funding.

\section{REFERENCES}

AOAC International. 2012. Official Methods of Analysis 19th ed. AOAC Int., Arlington, VA.

ASABE. 2007. Method of determining and expressing fineness of feed materials by sieving. ANSI/ASAE S319.4:646-649. Am. Soc. Ag. Biol. Eng., St. Joseph, MI.

Bach Knudsen, K. E. 1997. Carbohydrate and lignin contents of plant materials used in animal feeding. Anim. Feed Sci. Technol. 67:319338.

Baker, S., and T. Herrman. 2002. Evaluating particle size. MF-2051. Kansas State Univ., Manhattan.

Bal, M. A., R. D. Shaver, A. G. Jirovec, K. J. Shinners, and J. G. Coors. 2000. Crop processing and chop length of corn silage: Effects on intake, digestion, and milk production by dairy cows. J. Dairy Sci. 83:1264-1273.

Cherney, D. J. R., J. A. Patterson, and R. P. Lemenager. 1990. Influence of in situ bag rinsing technique on determination of dry matter disappearance. J. Dairy Sci. 73:391-397.

Clementson, C. L., and K. E. Ileleji. 2012. Particle heterogeneity of corn distillers dried grains with solubles (DDGS). Bioresour. Technol. 107:213-221.

Cooke, K. M., and J. K. Bernard. 2005. Effect of kernel processing and theoretical length of cut of corn silage on performance of lactating dairy cows. J. Dairy Sci. 88:310-316.

Correa, C. E. S., R. D. Shaver, M. N. Pereira, J. G. Lauer, and K. Kohn. 2002. Relationship between corn vitreousness and ruminal in situ starch degradability. J. Dairy Sci. 85:3008-3012.

EnayatGholizadeh, M. R., A. M. Bakhshandeh, M. D. Shoar, M. H. Ghaineh, K. H. A. Saeid, and M. Sharafizadeh. 2012. Effect of source and seed size on yield component of corn S.C704 in Khuzestan. Afr. J. Biotechnol. 11:2938-2944.

Ferraretto, L. F., P. M. Crump, and R. D. Shaver. 2013. Effect of cereal grain type and corn grain harvesting and processing methods on intake, digestion, and milk production by dairy cows through a meta-analysis. J. Dairy Sci. 96:533-550.

Ferraretto, L. F., and R. D. Shaver. 2012a. Effect of corn shredlage on lactation performance and total tract starch digestibility by dairy cows. Prof. Anim. Sci. 28:639-647.

Ferraretto, L. F., and R. D. Shaver. 2012b. Meta-analysis: Effect of corn silage harvest practices on intake, digestion, and milk production by dairy cows. Prof. Anim. Sci. 28:141-149.

Ferraretto, L. F., K. Taysom, D. Taysom, R. D. Shaver, and P. C. Hoffman. 2014. Relationship between dry matter content, ensiling, ammonia-nitrogen, and ruminal in vitro starch digestibility in high-moisture corn samples. J. Dairy Sci. 97:3221-3227.

Ferreira, G., and D. R. Mertens. 2005. Chemical and physical characteristics of corn silages and their effects of in vitro disappearance. J. Dairy Sci. 88:4414-4425.

Graven, L. M., and P. R. Carter. 1990. Seed size, shape and tillage system effect on corn growth and grain yield. J. Prod. Agric. $3: 445-452$.

Hoffman, P. C., N. M. Esser, R. D. Shaver, W. K. Coblentz, M. P. Scott, A. L. Bodnar, R. J. Schmidt, and R. C. Charley. 2011. Influence of ensiling time and inoculation on alteration of the starchprotein matrix in high-moisture corn. J. Dairy Sci. 94:2465-2474.

Hoffman, P. C., D. R. Mertens, J. Larson, W. K. Coblentz, and R. D Shaver. 2012a. A query for effective mean particle size of dry and high moisture corns. J. Dairy Sci. 95:3467-3477.

Hoffman, P. C., R. D. Shaver, and D. R. Mertens. 2012b. Feed Grain V2.0 Evaluation System. Accessed Jul. 8, 2015. http://shaverlab. dysci.wisc.edu/spreadsheets/.

Hoffman, P. C., R. D. Shaver, and D. R. Mertens. 2012c. Feed Grain V2.0 Evaluation System Background and Development Guide. Accessed Aug. 14, 2015. http://shaverlab.dysci.wisc.edu/wp-content/ uploads/sites/87/2015/04/Background-DevelopmentGuidev2.0b1. pdf.

Holm, S. 1979. A simple sequentially rejective multiple test procedure. Scand. J. Stat. 6:65-70.

Huntington, G. B. 1997. Starch utilization by ruminants: From basics to the bunk. J. Anim. Sci. 75:852-867.

Johnson, L. M., J. H. Harrison, D. Davidson, J. Robutti, M. Swift, B. Mahanna, and K. Shinners. 2002. Corn silage management I: Effects of hybrid, maturity, and mechanical processing on chemical and physical characteristics. J. Dairy Sci. 85:833-853.

Liu, K. 2008. Particle size distribution of distillers dried grains with solubles (DDGS) and relationships to compositional and color properties. Bioresour. Technol. 99:8421-8428.

McAllister, T. A., H. D. Bae, G. A. Jones, and K. J. Cheng. 1994 Microbial attachment and feed digestion in the rumen. J. Anim. Sci. 72:3004-3018.

McAllister, T. A., R. C. Phillippe, L. M. Rode, and K.-J. Cheng. 1993. Effect of the protein matrix on the digestion of cereal grains by ruminal microorganisms. J. Anim. Sci. 71:205-212.

Mentink, R. L., P. C. Hoffman, and L. M. Bauman. 2006. Utility of near-infrared reflectance spectroscopy to predict nutrient composition and in vitro digestibility of total mixed rations. J. Dairy Sci. 89:2320-2326.

Mondo, V. H. V., S. M. Cicero, D. Dourado-Neto, T. Pupim, and M. A. N. Dias. 2013. Effect of seed vigor on intraspecific competition and grain yield in maize. Agron. J. 105:222-228.

NRC. 2001. Nutrient Requirements of Dairy Cattle. 7th rev. ed. Natl. Acad. Sci., Washington, DC.

Ngonyamo-Majee, D., R. D. Shaver, J. G. Coors, D. Sapienza, and J. G. Lauer. 2008. Relationships between kernel vitreousness and dry matter degradability for diverse corn germplasm: II. Ruminal and post-ruminal degradabilities. Anim. Feed Sci. Technol. 142:259-274.

Ngonyamo-Majee, D., R. D. Shaver, J. G. Coors, D. Sapienza, and J. G. Lauer. 2009. Influence of single-gene mutations, harvest maturity and sample processing on ruminal in situ and post-ruminal in vitro dry matter and starch degradability of corn grain by ruminants. Anim. Feed Sci. Technol. 151:240-259. 
Philippeau, C., and B. Michalet-Doreau. 1997. Influence of genotype and stage of maturity of maize on rate of ruminal starch degradation. Anim. Feed Sci. Technol. 68:25-35.

Philippeau, C., and B. Michalet-Doreau. 1998. Influence of genotype and ensiling of corn grain on in situ degradation of starch in the rumen. J. Dairy Sci. 81:2178-2184.

Philippeau, C., and B. Michalet-Doreau. 1999. Relationship between ruminal starch degradation and the physical characteristics of corn grain. J. Anim. Sci. 77:238-243.

Salvati, G. G. S., L. F. Ferraretto, R. D. Shaver, M. Lippert, E. Ronk, and C. Wacek-Driver. 2015. Corn silage processing: Dairy farm survey. Pages 300-301 in Proc. XVII International Silage Conference, Piracicaba, SP, Brazil. ESALQ, Piracicaba, SP, Brazil.

SAS Institute. 2004. SAS/STAT 9.1 User's Guide. Version 9.1 ed. SAS Institute Inc., Cary, NC.
Savoie, P., K. J. Shinners, and B. N. Binversie. 2004. Hydrodynamic separation of grain and stover components in corn silage. Appl. Biochem. Biotechnol. 113-116:41-54.

Shinners, K. J., A. G. Jirovec, R. D. Shaver, and M. Bal. 2000. Processing whole-plant corn silage with crop processing rolls on a pulltype forage harvester. Appl. Eng. Agric. 16:323-331.

Vanderwerff, L. M., L. F. Ferraretto, and R. D. Shaver. 2015. Brown midrib corn shredlage in diets for high-producing dairy cows. J. Dairy Sci. 98:5642-5652.

Zwald, A., A. E. Dorshorst, P. C. Hoffman, L. M. Bauman, and M. G. Bertram. 2008. Technical Note: A near infrared reflectance spectroscopy technique to predict particle size of starch within corn silage. J. Dairy Sci. 91:2071-2076. 